\title{
Economic burden of COPD in a Swedish cohort: the ARCTIC study
}

This article was published in the following Dove Press journal:

International Journal of COPD

\author{
Karin Lisspers ${ }^{1}$ \\ Kjell Larsson ${ }^{2}$ \\ Gunnar Johansson' \\ Christer Janson ${ }^{3}$ \\ Madlaina Costa-Scharplatz ${ }^{4}$ \\ Jean-Bernard Gruenberger ${ }^{5}$ \\ Milica Uhde ${ }^{6}$ \\ Leif Jorgensen ${ }^{7}$ \\ Florian S Gutzwiller ${ }^{5}$ \\ Björn Ställberg' \\ 'Department of Public Health and \\ Caring Sciences, Family Medicine \\ and Preventive Medicine, Uppsala \\ University, Uppsala, ${ }^{2}$ Department \\ of Work Environment Toxicology, \\ The National Institute of \\ Environmental Medicine, Karolinska \\ Institute, Solna, ${ }^{3}$ Department of \\ Medical Sciences, Respiratory, \\ Allergy and Sleep Research, Uppsala \\ University, Uppsala, ${ }^{4}$ Novartis $A B$, \\ Täby, Sweden; ${ }^{5}$ Novartis, Basel, \\ Switzerland; ' $V$ QVIA, Solna, Sweden; \\ 'IQVIA, Copenhagen, Denmark
}

Correspondence: Karin Lisspers Department of Public Health and Caring Sciences, Family Medicine and Preventive Medicine, Uppsala University, Box 564, SE-75I 22 Uppsala, Sweden

Tel +46 70352472I

Email karin.lisspers@Ittalarna.se
Background: We assessed direct and indirect costs associated with COPD in Sweden and examined how these costs vary across time, age, and disease stage in a cohort of patients with COPD and matched controls in a real-world, primary care (PC) setting.

Patients and methods: Data from electronic medical records linked to the mandatory national health registers were collected for COPD patients and a matched reference population in $52 \mathrm{PC}$ centers from 2000 to 2014. Direct health care costs (drug, outpatient or inpatient, PC, both COPD related and not COPD related) and indirect health care costs (loss of income, absenteeism, loss of productivity) were assessed.

Results: A total of 17,479 patients with COPD and 84,514 reference controls were analyzed. During 2013, direct costs were considerably higher among the COPD patient population $(€ 13,179)$ versus the reference population $(€ 2,716)$, largely due to hospital nights unrelated to COPD. Direct costs increased with increasing disease severity and increasing age and were driven by higher respiratory drug costs and non-COPD-related hospital nights. Indirect costs ( $€ 28,000$ per patient) were the largest economic burden in COPD patients of working age during 2013.

Conclusion: As non-COPD-related hospital nights represent the largest direct cost, management of comorbidities in COPD would offer clinical benefits and relieve the financial burden of disease.

Keywords: COPD, direct cost, indirect cost, burden, Sweden

\section{Introduction}

COPD is a common, preventable, and treatable disease that is characterized by persistent respiratory symptoms and airflow limitation that is due to airway and/or alveolar abnormalities usually caused by significant exposure to noxious particles or gases. ${ }^{1}$ There is a high and growing prevalence of COPD globally and notably over the past 2 decades; prevalence has increased more rapidly among women than men. ${ }^{2}$ Although the data vary greatly depending on the survey methods, analytical approaches, and other factors, ${ }^{3}$ the estimated worldwide prevalence of spirometry-defined COPD was $11.7 \%$ in $2010 .{ }^{4}$ COPD is a major cause of chronic morbidity and mortality, and in Sweden, life expectancy of patients with COPD is on average 8 years shorter than that in the general population, with all-cause mortality being 3.5 times higher. ${ }^{5} \mathrm{COPD}$ is often associated with significant comorbidities including cardiovascular disease, diabetes, hypertension, depression, anxiety, and osteoporosis. ${ }^{6-8}$

COPD also carries an enormous societal economic burden. Across Europe in 2011, the total annual direct health care costs for inpatient and outpatient care, primary care (PC), and drug costs were estimated to be $€ 23.3$ billion. ${ }^{3}$ The true economic burden of COPD should also reflect indirect costs including loss of income (for both patients with 
COPD and family caregivers) and employer-related costs (lost productivity through work absenteeism, impaired work performance). ${ }^{9}$ Indeed, indirect costs (absence from work, early retirement) of COPD in Europe in 2011 were estimated to be greater than direct costs, amounting to $€ 25.1$ billion. $^{3}$

A majority of patients with COPD in Sweden are managed in PC. ${ }^{10}$ During an acute exacerbation, patients present at their primary health care center or at the hospital emergency department. ${ }^{11}$ Most PC centers in Sweden have spirometers and specialized asthma/COPD nurses who provide customized care. ${ }^{10}$ Annual societal costs of COPD in Sweden in 2010 were estimated at $€ 1.5$ billion, and similar to the picture globally, indirect costs were higher than direct costs of the disease, accounting for $65 \%$ and $35 \%$ of the total costs, respectively. ${ }^{12}$

It is important to better understand the economic burden of COPD in Sweden regarding direct and indirect cost drivers, particularly how these costs differ between patients with/without COPD. This knowledge is essential to inform policy decisions regarding strategic planning, management, and allocation of resources; estimating the health care costs associated with the various components of COPD helps decision makers target necessary interventions to those areas with the potential for greatest impact on overall diseaserelated costs. ${ }^{13}$

The aims of this study were to assess the direct and indirect costs associated with COPD in Sweden and to examine how these costs vary across time, age, and disease severity in patients with COPD and matched controls in a PC setting.

\section{Patients and methods Study design}

This was a real-world, retrospective, observational cohort study of patients with COPD managed in PC in Sweden and an age- and sex-matched reference population. Ethical approval of the study was received from the local ethical regional board in Uppsala, Sweden (number: 2014-397). All data were de-identified, and therefore, patient consent was not required by the ethics committee.

Following ethical approval, data from electronic medical records (EMRs) were collected for patients (COPD and reference populations) from 52 PC centers across Sweden between 2000 and 2014 by using an established software system (Pygargus Customized eXtraction Program [CXP] 3.0), and included age and sex, prescriptions (according to the World Health Organization [WHO] Anatomic Therapeutic Chemical [ATC] codes), diagnoses (according to the International Classification of Diseases, tenth edition
[ICD-10] codes), spirometry measurements, laboratory tests, health care professional (HCP) visits, and referrals. The centers covered urban and rural sites of varying sizes across Sweden. EMR data were linked by the Swedish National Board of Health and Welfare by using individual patient identification (ID) numbers to the data sources of the national registry (patient IDs were pseudonymized): 1) the Longitudinal Integration Database for Health Insurance and Labor Market Studies (LISA), ${ }^{14}$ which comprises sociodemographic data, including educational level, marital status and family situation, occupational status, retirement, economic compensation, and social benefits; 2) the National Patient Register, ${ }^{15}$ which contains data relating to diagnosis (ICD-10 code and associated position), surgery, sex, age, region, hospital visits, specialty visits, hospital admissions and discharges, and medical procedures and surgeries performed in the inpatient and outpatient specialist settings; 3 ) the National Prescription Register, ${ }^{15}$ which tracks the full details of all dispensed medications (ATC codes) in Sweden including brand name, prescription date, dose, strength, pack size, specialty of the prescriber, and costs associated with the drug prescription; and 4) the Cause of Death Register, ${ }^{15}$ which houses information relating to sex, date of death, and underlying cause of death.

\section{Study patients}

Patients aged $\geq 40$ years who had received a physician's diagnosis of COPD (ICD-10 J44) in PC (EMR database) or patients who had received a physician's diagnosis of COPD either in primary or secondary care (with or without a physician's diagnosis of asthma, ICD-10 J45/J46) were eligible for inclusion. To compare direct and indirect costs between COPD and non-COPD patients, a reference population from the same $P C$ centers was selected with a maximum of five patients for each COPD patient by using an age class of 1 year, sex, and year of COPD diagnosis (index year) as the classifying variables. The index year for patients in the reference population was assigned by calculating the length of the follow-up and assigning a random date (index date) within this time period. The year of the index date was used as the classifying variable for the index year for patients in the reference population to allow matching with the COPD patient population. All matching was performed after creation of the final research database.

\section{Outcomes}

Outcomes were direct costs on health care resource utilization (HCRU; COPD-related or -unrelated costs, drug costs, 
outpatient/inpatient costs, and PC costs) and indirect costs measured through loss of income in patients with COPD. Sick leave $>14$ days, receipt of social welfare benefits, and yearly income were also compared between the COPD patient and reference populations. Average exacerbation costs for moderate and severe exacerbations were calculated based on HCRU during 14 days after occurrence of an exacerbation event. Moderate exacerbations were defined as those requiring visits to a $\mathrm{PC}$ center and/or collection of oral corticosteroids or antibiotics targeted at respiratory diseases. Severe exacerbations were defined as those necessitating hospitalization due to COPD exacerbation in a secondary care center and/or emergency visits (outpatient hospital care). Recurrent exacerbations occurring within 14 days were considered as one unique event. If a patient experienced a severe exacerbation within 14 days of a single moderate exacerbation, the exacerbation was categorized as a severe exacerbation. Maintenance costs were calculated, defined as non-exacerbation-related COPD costs after the exclusion of COPD-related drug costs and annual moderate and severe exacerbation costs per patient. Maintenance costs comprised COPD-related hospital nights, hospital visits, and physician and nurse visits and comorbidity-related drugs, hospital nights, and hospital visits.

\section{Statistical analysis}

The statistical analysis software used was "PC SAS for Windows Version 9.3 (or higher)". Patient demographics were described for COPD patients and the reference population. The analysis for comparing costs between groups was done by an analysis of covariance with sum of the costs as the dependent variable and subgroup, age, and sex as covariates. Frequencies (eg, comorbidities) between groups were compared using the chi-square test. No correction for multiple comparisons was done, but all interpretations of results included both the $p$-value and medical judgments of the absolute difference between the groups. The indirect costs were calculated as "loss of income", ie, the average income of the reference population minus the observed average income in the COPD population where sick leave and early retirement were taken into consideration.

A sample size calculation conducted prior to the study indicated that 13,800 patients were required to detect a $4 \%$ difference between groups, with a power of $80 \%$ and an alpha level of $5 \%$ in a two-tailed test.

HCRU in terms of respiratory drug prescriptions and other drug prescriptions, hospital nights and hospital visits, physician visits and other HCP visits, income, welfare, and sick leave $>14$ days were each reported descriptively and stratified by disease status (COPD or reference population), disease severity, age group, and exacerbation phenotype (frequent exacerbators who experienced two or more exacerbations per year or non-frequent exacerbators who experienced less than two exacerbations per year). Both HCRU and productivity loss (loss of income from work) were calculated for each disease stage, compared across the disease stages and compared with the reference population by using individual values. Analysis of variance (ANOVA) was used for age, number of hospitalizations, and inpatient and outpatient visits. The chi-square test was used for categorical variables, eg, sex, percentage of patients with prescriptions, and percentage of patients with hospitalizations.

The frequencies of comorbidities were calculated relative to the index date. An overall measure of comorbidities was calculated by the Charlson Comorbidity Index. ${ }^{16}$ Comorbidities were presented as the percentage of patients afflicted by various comorbidities. Prescriptions were calculated as the percentage of patients with a prescription in a 2 -year period prior to the index date.

\section{Results}

\section{Patients' demographics}

A total of 18,586 patients with COPD listed in EMRs were preliminarily identified as eligible for inclusion in the study, with 291 patients excluded as they were diagnosed with COPD before 40 years of age. Following case-control matching, there were 17,479 patients with COPD (COPD population) and 84,514 control patients (reference population). Baseline characteristics for both study populations are presented in Table 1. The mean age of patients was 65 years, with a higher proportion of females $(56.5 \%)$ to males $(43.5 \%)$. The COPD population had a significantly greater number of comorbidities compared with the reference population, and there were significantly higher levels of HCRU and medication use among the COPD population compared with the reference group (Table 1).

\section{Total direct and indirect health care costs}

Direct health care costs stratified by COPD and reference populations during 2013 (the year with the most recent complete data set) are reported in Table 2 and Figure 1. Total direct health care costs were higher for the COPD patient population $(€ 13,179)$ compared with the reference population ( $€ 2,716 ; 2013$ exchange rate, 8 Swedish krona to 1 euro). Direct costs for the COPD population were driven largely by the higher costs associated with non-COPD-related nights 
Table I Patient demographics of the COPD population and the age- and sex-matched reference population

\begin{tabular}{|c|c|c|c|}
\hline Variable $^{a}$ & $\begin{array}{l}\text { COPD patients } \\
(n=17,479)\end{array}$ & $\begin{array}{l}\text { Reference population } \\
(n=84,5 ! 4)\end{array}$ & p-value \\
\hline \multicolumn{4}{|l|}{ Age (years) } \\
\hline Mean (SD) & $65.0(11.90)$ & $65.0(11.90)$ & \\
\hline \multicolumn{4}{|l|}{ Sex } \\
\hline Female, $\mathrm{n}(\%)$ & $9,88 \mathrm{I}(56.53)$ & $47,777(56.53)$ & \\
\hline Male, n (\%) & $7,598(43.47)$ & $36,737(43.47)$ & \\
\hline \multicolumn{4}{|l|}{ Health care utilization } \\
\hline Outpatient visits per year & 1.78 & 1.50 & $<0.0001$ \\
\hline Number of PC contacts per year & 10.0 & 4.83 & $<0.0001$ \\
\hline Patients with overnight stays, $\mathrm{n}(\%)$ & $6,042(34.57)$ & $19,497(23.09)$ & $<0.000$ I \\
\hline Patients with outpatient hospital visits, n (\%) & $10,575(60.50)$ & $48,657(57.61)$ & $<0.000$ I \\
\hline Days of sick leave in 2013, mean $^{\mathrm{b}}$ & 30.3 & 16.4 & \\
\hline People in receipt of social welfare in $2013, \%$ & 67.5 & 39.8 & \\
\hline Number of Charlson comorbidity groups & 1.60 & 1.27 & $<0.0001$ \\
\hline Charlson Comorbidity Index value & 1.70 & 1.33 & $<0.0001$ \\
\hline \multicolumn{4}{|l|}{ Comorbidities, n (\%) } \\
\hline Asthma & $2,53 \mid(\mid 4.48)$ & $4,077(4.83)$ & $<0.0001$ \\
\hline Cardiovascular diseases $^{c}$ & $6,736(38.54)$ & $19,572(23.17)$ & $<0.000$ I \\
\hline Ischemic heart diseases ${ }^{d}$ & $1,815(10.38)$ & $4, I I I(4.87)$ & $<0.000$ I \\
\hline Hypertensive diseases ${ }^{\mathrm{e}}$ & $4,019(22.99)$ & II,693 (I3.85) & $<0.0001$ \\
\hline Other forms of heart diseases ${ }^{f}$ & $2,504(14.33)$ & $5,388(6.38)$ & $<0.0001$ \\
\hline Hyperlipidemia & $385(2.20)$ & $976(1.16)$ & $<0.000$ I \\
\hline Diabetes, type I & $340(1.95)$ & $\mathrm{I}, 420(\mathrm{I} .68)$ & 0.0148 \\
\hline Diabetes, type II & $1,253(7.17)$ & $3,859(4.57)$ & $<0.000$ I \\
\hline Depression & $962(5.50)$ & $2,178(2.58)$ & $<0.000$ I \\
\hline Osteoporosis & $397(2.27)$ & $866(1.03)$ & $<0.000$ I \\
\hline Fractures & $1,126(6.44)$ & $4,069(4.82)$ & $<0.000$ I \\
\hline Respiratory diseases ${ }^{g}$ & $6,382(36.5 I)$ & $11,150(13.20)$ & $<0.0001$ \\
\hline \multicolumn{4}{|l|}{ Medication use during follow-up, n (\%) } \\
\hline Beta-blocking agents & $4,401(25.18)$ & $14,834(\mid 7.56)$ & $<0.0001$ \\
\hline Antidepressants & $3,418(19.55)$ & $9,906(11.73)$ & $<0.0001$ \\
\hline Statins & $3,228(18.47)$ & $12,786(15.14)$ & $<0.0001$ \\
\hline Diabetes medication & I,565 (8.95) & $5,869(6.95)$ & $<0.000$ I \\
\hline Antibiotic for airways & $5,273(30.17)$ & $12,213(14.46)$ & $<0.000$ I \\
\hline Oral steroids & $3,116(17.83)$ & $6,250(7.40)$ & $<0.0001$ \\
\hline Low-dose ICS h & $5,132(29.36)$ & $10,619(12.56)$ & $<0.0001$ \\
\hline High-dose ICS & $2,927(16.75)$ & $4,170(4.93)$ & $<0.0001$ \\
\hline
\end{tabular}

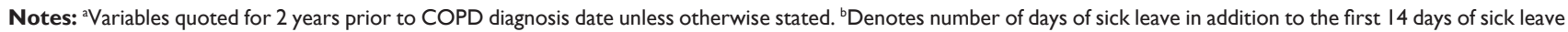
paid for by an employer. Includes diseases of the circulatory system, 100-199. Includes but not limited to angina pectoris, acute myocardial infarction, other acute ischemic heart diseases, and chronic ischemic heart diseases, 120-125. encludes hypertensive heart disease, hypertensive renal disease, hypertensive heart and renal disease, primary hypertension, and secondary hypertension, II0-115. IIncludes but not limited to heart failure, atrial fibrillation and flutter, other cardiac arrhythmias, cardiac arrest, and cardiomyopathy, I30-152. IIncludes diseases of the respiratory system, J00-J99. 'Low-dose ICS, <640 $\mu \mathrm{g}$ budesonide or equivalent/day; high-dose ICS, $>640 \mu \mathrm{g}$ budesonide or equivalent/day.

Abbreviations: SD, standard deviation; PC, primary care; ICS, inhaled corticosteroid.

in hospital, ie, due to comorbidities (Figure 1). Direct costs increased with increasing disease severity during 2013 and were driven by higher costs for respiratory drugs and hospital nights unrelated to COPD (Figure 2).

Direct costs increased with age during 2013 and were lowest in the $45-<50$-year age group and highest in the $85+$ year age group (Figure 3). Costs for hospital nights for reasons not related to COPD were the greatest cost driver among the age groups. These direct costs increased with age, with the lowest costs in the $45-<50$-year age group and the highest costs in the $85+$ year age group (Figure 3 ).

COPD patients classed as frequent exacerbators had considerably higher direct health care costs at all time points compared with non-frequent exacerbators (Figure 4), with costs of $€ 23,939$ and $€ 9,487$ attributable to frequent and non-frequent exacerbations, respectively, during 2013.

Indirect costs (loss of income) were the largest single financial burden for COPD patients of working age (aged 
Table 2 Direct costs per patient (in euros [€]) stratified by the COPD and reference populations during 2013

\begin{tabular}{lll}
\hline Cost category & $\begin{array}{l}\text { COPD } \\
\text { patients } \\
(\mathbf{n}=\mathbf{7 , 2 5} \text { I) }\end{array}$ & $\begin{array}{l}\text { Reference } \\
\text { population } \\
(\mathbf{n}=\mathbf{4} \text { I, I I I ) }\end{array}$ \\
\hline Respiratory drugs & 584 & 50 \\
All drugs & 438 & 206 \\
Hospital nights (COPD related) & 620 & 68 \\
Hospital nights (non-COPD) & 8,295 & 1,285 \\
Hospital visits (COPD related) & 34 & 4 \\
Hospital visits (non-COPD) & 1,245 & 589 \\
PC visits (physician) & 1,453 & 402 \\
PC visits (non-physician) & 510 & 112 \\
Total & 13,179 & 2,716 \\
\hline
\end{tabular}

Notes: All costs were significantly higher for COPD patients compared to reference population (all $p$-values $<0.0001$ ). Unit costs are (SEK, 2013 rates) 9,580 SEK for hospital nights, 3,000 SEK for hospital visits, and I,462 SEK for physician and 596 SEK for non-physician PC visits. Exchange rate in 2013: 8 SEK =I euro Abbreviations: PC, primary care; SEK, Swedish krona.

$45-<65$ years) during 2013 (Figure 3). The $50-<55$-year age group experienced the greatest economic burden with total costs amounting to an average of $\sim € 36,000$ per patient ( $€ 28,000$ indirect costs and $\sim € 8,000$ direct costs).

A comparison of incomes revealed that the reference population had higher levels of income that increased over time compared with the COPD population whose income levels remained static over time (Figure 5A). A more than twofold difference was observed in the annual income between the COPD and reference populations during 2013 ( $€ 12,878$ vs $€ 29,686$, respectively). The COPD population had a higher average number of sick days than the reference population (Figure 5B). A higher percentage of the COPD population received social welfare income compared with the reference population, although little change was observed over time in the proportion of patients in either population receiving social welfare (Figure $5 \mathrm{C}$ ).

The detailed costs of exacerbations per occurrence during 2013 are reported in Table 3. A major driver of total direct costs was the cost of severe exacerbations. In addition, the cost of severe exacerbations increased with disease severity.

Non-exacerbation-related maintenance costs during 2013 are reported in Table 3. Costs were similar for the mild, moderate, and severe COPD populations, with costs for the very severe COPD population being marginally higher.

\section{Discussion}

This study has demonstrated the significant economic burden of COPD in patients from 52 PC centers across Sweden, consistent with the global picture, ${ }^{17}$ with the poor health of COPD patients reflected by the magnitude of the direct and indirect health care costs associated with these patients. Total direct costs were considerably higher among the COPD patient population compared with the reference population, with an approximate fivefold difference between the two populations. These direct costs, driven largely by hospital nights that were related to comorbidities, increased with age and with disease severity. Indirect costs were the single largest economic burden in COPD patients of working age.

This real-world study has provided a unique insight into the economic consequences of COPD in Sweden using a large sample size of high-quality national registry data from $\mathrm{PC}$ to evaluate the direct and indirect costs associated with COPD. In agreement with this study, a considerable number of studies have reported that COPD is a significant societal economic burden, associated with increased HCRU and higher health care costs, among COPD population versus control population. ${ }^{18-27}$ As in our observations, previous studies have reported that key drivers for higher direct costs of COPD include inpatient hospitalizations ${ }^{12,17,22,24,26,28}$ and increased medication use. ${ }^{12,17,18,24}$ Further contributory factors to higher direct costs in COPD patients are comorbidities ${ }^{17,19,23,27}$ and hospital admissions resulting from comorbidities. ${ }^{29,30}$ A previous population-based study conducted in Sweden

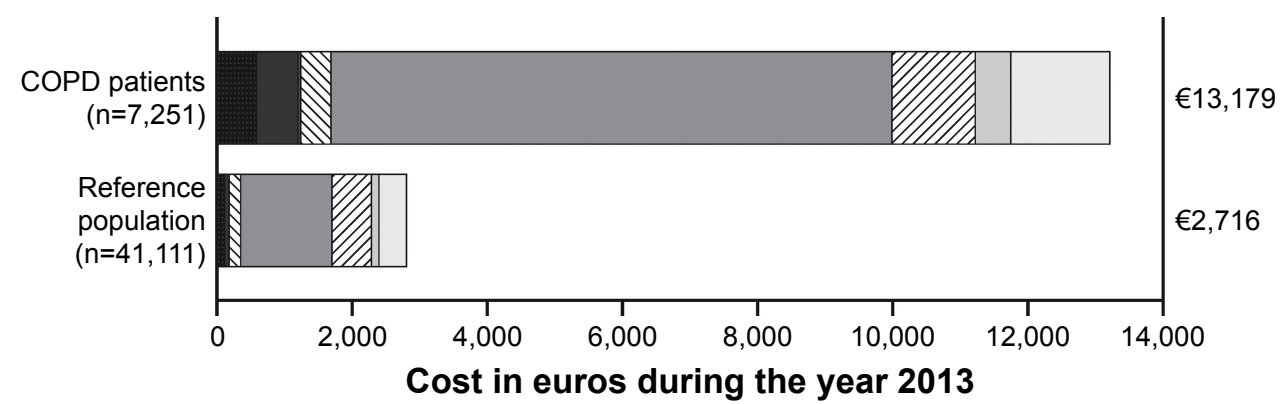

Respiratory drugs

Hospital nights, COPD

Hospital visit, COPD

Other drugs

Hospital nights, not COPD

Hospital visit, not COPD

PC, not physician

PC, physician

Figure I HCRU in euros $(€)$, stratified by COPD patients and reference patient population during 2013.

Note: HCRU was significantly higher for COPD patients compared to the reference population (all $p$-values $<0.000$ I).

Abbreviations: HCRU, health care resource utilization; PC, primary care. 


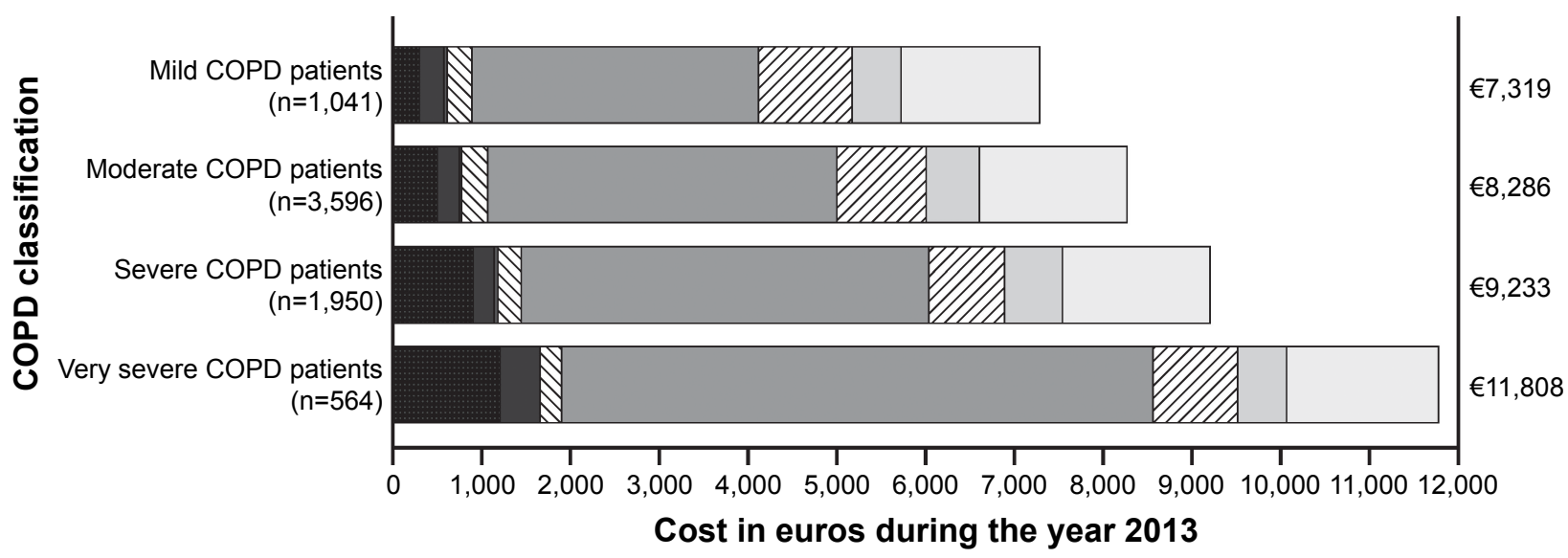

\begin{tabular}{|lll|}
\hline Respiratory drugs & Hospital nights, COPD & Hospital visit, COPD \\
$\mathbb{N}$ Other drugs & $\square$ Hospital nights, not COPD \\
$\square$ PC, not physician & $\square$ PC, physician
\end{tabular}

Figure 2 HCRU in euros (€), stratified by disease severity during 2013

Notes: Disease severity defined using GOLD 2009 and 2014 treatment guidelines: mild COPD, FEV,$\geq 80 \%$; moderate COPD, 50\% $\leq$ FEV $<80 \%$; severe COPD, $30 \% \leq \mathrm{FEV},<50 \%$; and very severe COPD, $\mathrm{FEV},<30 \%$. All costs increased significantly with COPD disease severity (all $p$-values $<0.000 \mathrm{I}$ ).

Abbreviations: HCRU, health care resource utilization; GOLD, Global Initiative for Chronic Obstructive Lung Disease; FEV PC, primary care.

also found that the total health care costs (for both respiratory and non-respiratory diseases, ie, comorbidities) were higher among COPD patients compared with non-COPD patients. ${ }^{31}$ Moreover, hospitalizations were more frequent and contributed to higher costs not only for respiratory but also non-respiratory conditions among the COPD population. Furthermore, hospitalization due to comorbid diseases was the main cost driver among COPD patients. ${ }^{31}$ Our results also highlight the important contribution of comorbidities to direct COPD costs. As the prevalence of comorbidities in patients with COPD is high, ${ }^{6}$ it would be negligent to disregard the potential impact of comorbidities on COPD health care costs. Reducing the risk of comorbidities and managing them more effectively would not only be of clinical benefit for the patients but should also relieve the financial burden of disease. ${ }^{17,32}$

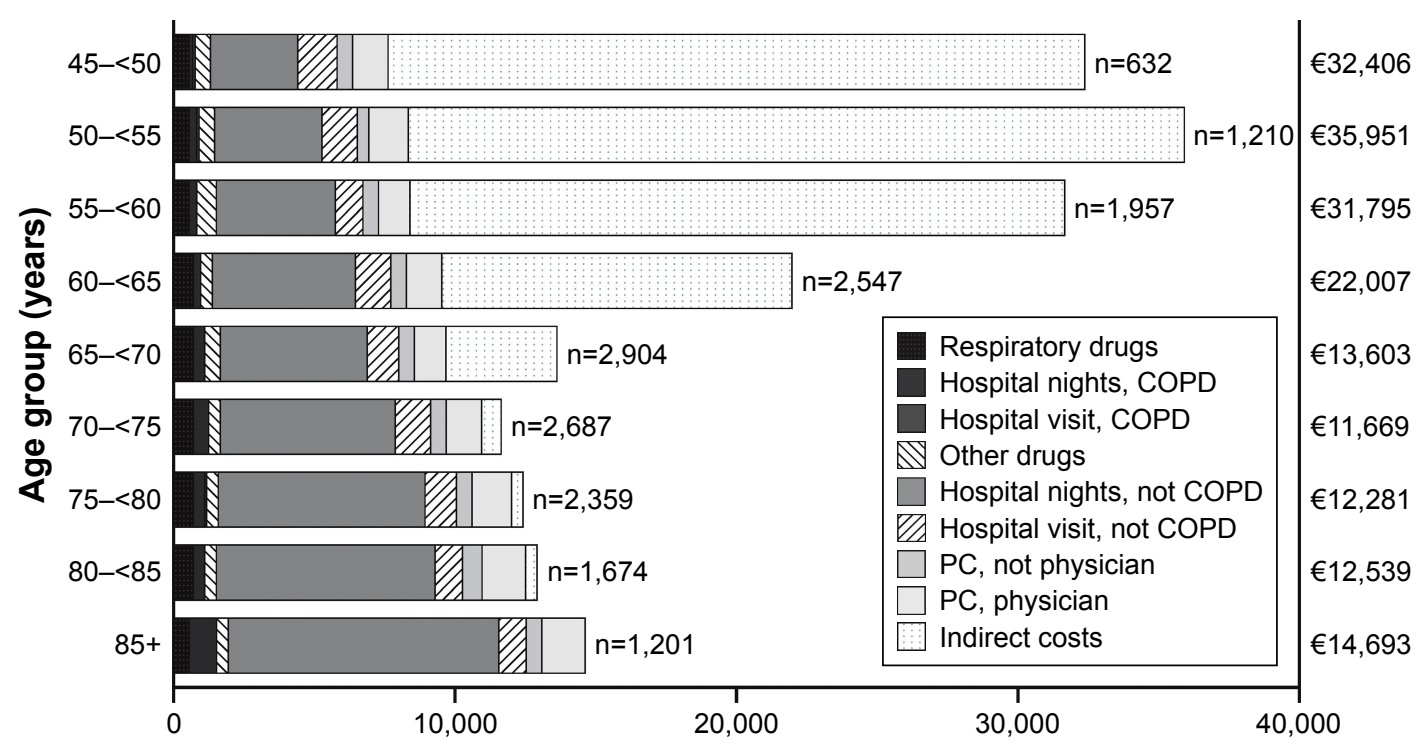

Cost in euros during the year 2013

Figure 3 Estimated direct and indirect costs in euros $(€)$ stratified by age group during 2013 in COPD patients. Abbreviation: PC, primary care. 


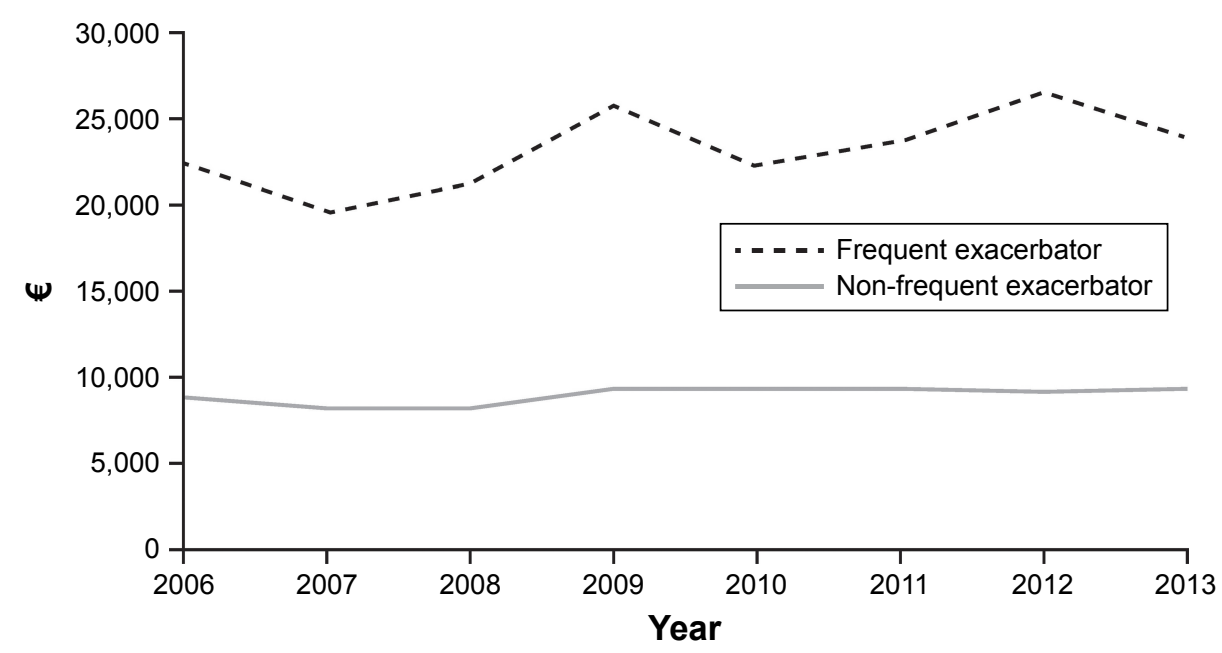

Figure 4 Yearly direct costs (euros [€]/year) stratified by frequent and non-frequent exacerbator phenotype (sum of drug costs and primary and secondary care costs). Note: Frequent exacerbator ( $\geq 2$ exacerbations per year) and non-frequent exacerbator ( $<2$ exacerbations per year).

The current findings support previous studies that have reported higher direct costs with increasing severity of disease. ${ }^{17,24,33}$ Earlier diagnosis and management of COPD would not only benefit patients but also reduce the economic burden of disease by interrupting the progression of mild and moderate COPD patients to severe stages of disease. ${ }^{33}$ This is supported by a Swedish burden of illness study that showed that total annual costs per patient with severe COPD decreased from 1999 to 2010, most likely due to a decreasing number of exacerbations, whereas annual costs per patient with mild or moderate COPD rose due to earlier diagnosis and treatment. ${ }^{12}$ Another previously published Swedish study also supports our results, showing that direct costs increased with increasing disease severity (ie, Global Initiative for Chronic Obstructive Lung Disease [GOLD] stage) among COPD patients. ${ }^{31}$ Exacerbations represent a significant economic burden on health care systems, with costs varying according to the frequency and severity of the exacerbation. ${ }^{34-36}$ Our study observed that frequent exacerbators had considerably higher direct health care costs versus non-frequent exacerbators, and the cost of severe exacerbations showed an overall trend toward an increase with disease severity. This is supported by comparable maintenance costs excluding exacerbations for all stages of disease severity. The blueprint for the successful management of exacerbations does exist already in Sweden, with a clear relationship between exacerbation rate and the presence of specialized asthma/COPD nurses within Swedish PC centers previously reported. ${ }^{10}$ The exacerbation rate was more than twice as high in those centers without the services of a specialized nurse. ${ }^{10}$ Earlier access to treatment, newer treatment options, greater patient reassurance, and earlier diagnosis of COPD may all improve management of exacerbations. ${ }^{5,10}$ Furthermore, the large, retrospective, observational PATHOS study found that primary health care centers with a dedicated asthma/COPD clinic reported fewer COPD exacerbations and substantially reduced overall treatment costs. ${ }^{37}$ More widespread access to asthma/COPD clinics within PC centers across Sweden could lead to improved exacerbation management, reducing both the clinical and economic burden of COPD.

This is the first study to provide an accurate measure of the indirect costs per patient associated with COPD in Sweden using EMR data linked to national health registers. Previous approximations of the annual economic burden of COPD in Sweden perhaps underplay the full contribution of indirect costs to total costs. ${ }^{3}$ Our study found that indirect costs (via loss of income) were approximately threefold higher versus direct costs in COPD patients of working age. Patients with COPD also had a larger number of sick days, received more social benefits, and earned a lower annual income than the reference population. Productivity loss due to work absenteeism and premature retirement are key drivers for higher indirect costs. ${ }^{9,12,19,25}$ A previous health economic study conducted in Sweden also demonstrated that the indirect costs account for $\sim 65 \%$ of the total costs, and the main cost drivers were productivity loss due to sick leave (for mild COPD) and early retirement (all other severity stages). ${ }^{12}$ Identifying strategies aimed at the prevention and early diagnosis of COPD may help patients continue to work and help mitigate costs, such as smoking cessation initiatives in the workplace, greater coordination of COPD management between employers and health care providers, and pulmonary rehabilitation programs. ${ }^{9,17}$ Determining indirect costs associated with COPD can be challenging, ${ }^{9}$ but it is clear that 

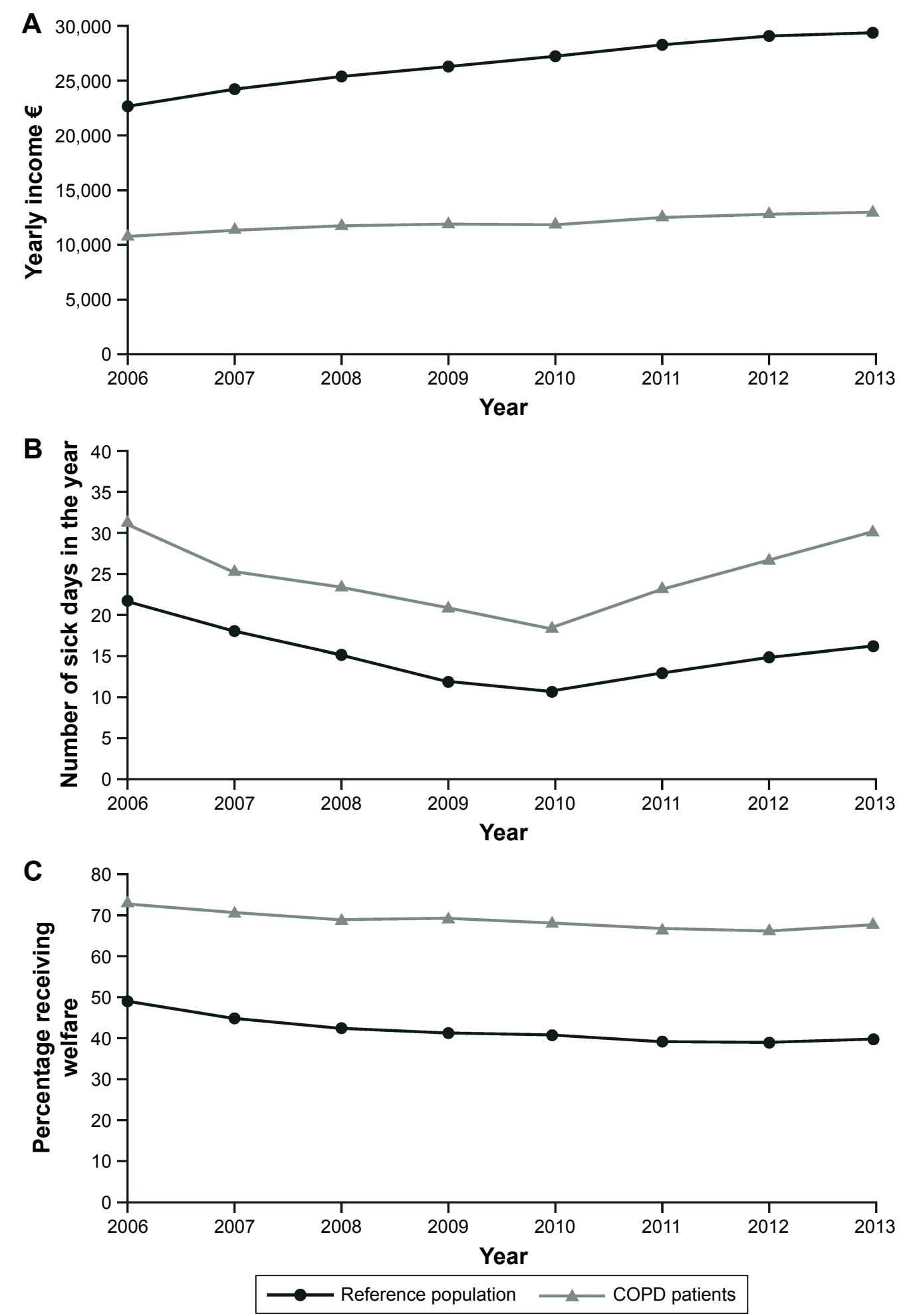

Figure $\mathbf{5}$ Yearly income in euros (€; A), number of sick days per year (B), and proportion of patients receiving social welfare each year (C), stratified by the COPD and reference patient populations.

Note: Social welfare included health insurance, benefits in respect of accidents at work or occupational diseases, disability benefits, old-age and survivors' benefits, unemployment insurance and family benefits, compensation for unemployment, sick leave support, early retirement, and support to rent an apartment.

they must be considered if we are to reveal the true societal economic burden of COPD.

There are a number of important strengths of this study. The large sample size (including patients across the COPD classification spectrum), PC setting, and real-world study design provide data that are highly reflective of the general population. ${ }^{37-39}$ The comprehensive range of outcomes measured and the extended assessment period (2000-2014) 
Table 3 Exacerbation costs (in euros [€]) per occurrence and non-exacerbation-related maintenance costs during 2013

\begin{tabular}{|c|c|c|c|c|c|}
\hline \multirow{2}{*}{$\begin{array}{l}\text { GOLD } 20 \text { I0 } \\
\text { classification of airflow } \\
\text { limitation }\end{array}$} & \multicolumn{2}{|c|}{ Cost per moderate exacerbation ${ }^{a}$} & \multirow{2}{*}{$\begin{array}{l}\begin{array}{l}\text { Cost per severe } \\
\text { exacerbation }\end{array} \\
\text { No of exacerbations } \\
\text { per group }\end{array}$} & \multicolumn{2}{|c|}{$\begin{array}{l}\text { Annual non-exacerbation- } \\
\text { related maintenance costs }\end{array}$} \\
\hline & $\begin{array}{l}\text { No of exacerbations } \\
\text { per group }\end{array}$ & Mean (SD), $€$ & & Mean (SD), $€$ & Mean, $€$ \\
\hline Mild COPD $(n=I, 04 I)$ & 852 & $532(808)$ & 24 & $5,475(4,975)$ & 6,474 \\
\hline Moderate COPD $(n=3,596)$ & 3,188 & $631(1,035)$ & 224 & $5,988(6,120)$ & 6,878 \\
\hline Severe COPD $(n=I, 950)$ & 2,139 & $614(825)$ & 330 & $5,992(5,951)$ & 6,674 \\
\hline Very severe COPD $(n=564)$ & 775 & $557(817)$ & 191 & $8,320(8,928)$ & 7,523 \\
\hline
\end{tabular}

Notes: Exchange rate in 2013, 8 SEK =I euro; recurrent exacerbations occurring within 14 days were considered as one unique event. aModerate exacerbation is defined by visits to PC (ICD- I0: J44) and/or collection of oral corticosteroids (ATC H02AB) or antibiotics targeted at respiratory diseases (ATC J0 IAA/J0 ICA). Moderate exacerbation cost comprises outpatient visits, nurse visits, physician visits, oral corticosteroids, and antibiotics targeted at respiratory diseases during 14 days after the exacerbation occurrence. 'Severe exacerbation is defined as hospitalization due to COPD exacerbation in secondary care (ICD- I0: J44.I) and/or emergency hospital visits (J44.I). Severe exacerbation cost comprises cost of hospital nights, outpatient visits, nurse visits, physician visits, oral corticosteroids, and/or antibiotics targeted at respiratory diseases during 14 days after the exacerbation occurrence.

Abbreviations: GOLD, Global Initiative for Chronic Obstructive Lung Disease; SD, standard deviation; SEK, Swedish krona; PC, primary care; ICD-I0, International Classification of Diseases, tenth edition; ATC, Anatomic Therapeutic Chemical.

generated robust economic data for COPD patients and matched controls across time, age, and disease stage. Finally, this study has recognized the importance of indirect costs in the economic burden of COPD on the Swedish society.

This study also has limitations. The retrospective design of the study means it may be subject to bias and confounding. Study results for absolute cost have limited generalizability outside of Sweden as cost structures, prices, and provision of PC differ between countries. Although extensive outcomes were measured, they were not exhaustive, and so some cost sources could have been missed (eg, personal care costs and costs attributable to family caregivers). The reference population was identified from patients without COPD who needed to attend the study PC centers rather than from healthy individuals in the general population.

\section{Conclusion}

The largest direct cost for COPD patients in this real-world Swedish study was hospital nights unrelated to COPD. Management of comorbidities in COPD patients is an important area of attention. A major driver of total direct costs is the cost of severe exacerbations. A reduction in exacerbations could therefore lead to economic benefit. Indirect costs represent the largest economic burden associated with COPD patients of working age.

As indicated by the study results, COPD presents a large economic burden. Hence, it is of utmost importance to increase awareness about COPD and to support primary and secondary prevention to reduce the growing prevalence of COPD in the society and to diagnose the disease at an early stage in patients who show signs and symptoms of COPD.

\section{Acknowledgments}

The authors were assisted in the preparation of the manuscript by Chris Cammack PhD and David McMinn PhD, professional medical writers at CircleScience, an Ashfield Company, part of UDG Healthcare plc (Tytherington, UK). The statistical analyses and medical writing support were funded by Novartis Pharma AG (Basel, Switzerland). The abstract of this paper was presented at the Nordic Lung Congress (NLC) 2017 as a poster presentation (P215) with interim findings (http://www.nlc2017.se/doc/Poster\%20 session\%20II.pdf); European Respiratory Society (ERS) International Congress 2016 as a poster presentation with interim findings and the poster abstract (PA3926) was published in "Poster Abstracts" in European Respiratory Journal (http://erj.ersjournals.com/content/48/suppl 60/PA3926, doi: 10.1183/13993003.congress-2016); International Primary Care Respiratory Group (IPCRG) Conference 2016 as an oral presentation with interim findings and the poster abstract (CR065) was published in "Poster Abstracts" in $n p j$ Primary Care Respiratory Medicine (https://images.nature. com/full/nature-assets/npjpcrm/abstracts/npjpcrm201622. pdf, doi:10.1038/npjpcrm.2016.22).

\section{Disclosure}

Karin Lisspers has received honoraria for educational activities and lectures from AstraZeneca, GlaxoSmithKline, Novartis, MEDA, and Takeda and has served on advisory boards arranged by MEDA and Novartis. She has also participated in the steering committee for this study funded by Novartis. Kjell Larsson has, during the last 5 years, on one or more occasion served in an advisory board, served as a speaker, and/or participated in education arranged by AstraZeneca, Boehringer Ingelheim, GlaxoSmithKline, Takeda, Novartis, Chiesi, Orion and Teva. Gunnar Johansson has participated in the steering committee organized by Novartis for this study and served on advisory boards arranged by Astra Zeneca, Novo Nordisk, and Takeda. 
Christer Janson has received honoraria for educational activities and lectures from Novartis, AstraZeneca, GlaxoSmithKline, and Boehringer Ingelheim outside the submitted work. Björn Ställberg has received honoraria for educational activities and lectures from AstraZeneca, Boehringer Ingelheim, GlaxoSmithKline, Novartis, MEDA, and TEVA and has served on advisory boards arranged by AstraZeneca, Novartis, GSK, Boehringer Ingelheim and MEDA. Florian S Gutzwiller, and Jean-Bernard Gruenberger are employees of Novartis Pharma AG. Madlaina Costa-Scharplatz is an employee of Novartis AB. Milica Uhde and Leif Jorgensen are employees of IQVIA, who received remuneration in relation to statistical analysis. The authors report no other conflicts of interest in this work.

\section{References}

1. Global Initiative for Chronic Obstructive Lung Disease (GOLD). Global Strategy for the Diagnosis, Management, and Prevention of Chronic Obstructive Pulmonary Disease [updated 2017]. Available from: http://goldcopd.org/gold-2017-global-strategy-diagnosis-managementprevention-copd/. Accessed January 3, 2017.

2. Aryal S, Diaz-Guzman E, Mannino DM. Influence of sex on chronic obstructive pulmonary disease risk and treatment outcomes. Int J Chron Obstruct Pulmon Dis. 2014;9(1):1145-1154.

3. European Respiratory Society (ERS) [webpage on the Internet]. European Lung White Book-Chapter 2: The Economic Burden of Lung Disease [updated 2016]. Available from: http://www.erswhitebook.org/chapters/ the-economic-burden-of-lung-disease/. Accessed October 12, 2016.

4. Adeloye D, Chua S, Lee C, et al. Global and regional estimates of COPD prevalence: systematic review and meta-analysis. J Glob Health. 2015;5(2):020415.

5. Stallberg B, Janson C, Johansson G, et al. Management, morbidity and mortality of COPD during an 11-year period: an observational retrospective epidemiological register study in Sweden (PATHOS). Prim Care Respir J. 2014;23(1):38-45.

6. Mannino DM, Thorn D, Swensen A, Holguin F. Prevalence and outcomes of diabetes, hypertension and cardiovascular disease in COPD. Eur Respir J. 2008;32(4):962-969.

7. Yohannes AM, Alexopoulos GS. Depression and anxiety in patients with COPD. Eur Respir Rev. 2014;23(133):345-349.

8. Sarkar M, Bhardwaj R, Madabhavi I, Khatana J. Osteoporosis in chronic obstructive pulmonary disease. Clin Med Insights Circ Respir Pulm Med. 2015;9:5-21.

9. Patel JG, Nagar SP, Dalal AA. Indirect costs in chronic obstructive pulmonary disease: a review of the economic burden on employers and individuals in the United States. Int J Chron Obstruct Pulmon Dis. 2014;9(1):289-300.

10. Lofdahl CG, Tilling B, Ekstrom T, Jorgensen L, Johansson G, Larsson K. COPD health care in Sweden - a study in primary and secondary care. Respir Med. 2010;104(3):404-411.

11. Sundh J, Osterlund Efraimsson E, Janson C, Montgomery S, Stallberg B, Lisspers K. Management of COPD exacerbations in primary care: a clinical cohort study. Prim Care Respir J. 2013;22(4):393-399.

12. Jansson SA, Backman H, Stenling A, Lindberg A, Ronmark E, Lundback B. Health economic costs of COPD in Sweden by disease severity - has it changed during a ten years period? Respir Med. 2013; 107(12):1931-1938.

13. Chapman KR, Mannino DM, Soriano JB, et al. Epidemiology and costs of chronic obstructive pulmonary disease. Eur Respir J. 2006;27(1): 188-207.
14. Statistics Sweden [webpage on the Internet]. Longitudinal Integration Database for Health Insurance and Labour Market Studies [LISA by Swedish acronym 2004]. Available from: https://www.scb.se/ en_/Services/Guidance-for-researchers-and-universities/SCBData/Longitudinal-integration-database-for-health-insurance-andlabour-market-studies-LISA-by-Swedish-acronym/. Accessed June 26, 2017.

15. Socialstyrelsen [homepage on the Internet]. Available from: http:// www.socialstyrelsen.se/register. Accessed June 26, 2017.

16. University of Manitoba - Community of Health Sciences - Manitoba Center for Health Policy [webpage on the Internet]. Concept Description: Charlson Comorbidity Index [updated January 22, 2016]. Available from: $\mathrm{http}: / / \mathrm{mchp}$-appserv.cpe.umanitoba.ca/viewConcept. php?conceptID=1098. Accessed June 26, 2017.

17. Foo J, Landis SH, Maskell J, et al. Continuing to confront COPD international patient survey: economic impact of COPD in 12 countries. PLoS One. 2016;11(4):e0152618.

18. Lokke A, Hilberg O, Tonnesen P, Ibsen R, Kjellberg J, Jennum P. Direct and indirect economic and health consequences of COPD in Denmark: a national register-based study: 1998-2010. BMJ Open. 2014; 4(1):e004069.

19. Wacker ME, Jorres RA, Schulz H, et al. Direct and indirect costs of COPD and its comorbidities: results from the German COSYCONET study. Respir Med. 2016;111:39-46.

20. Mapel DW, Hurley JS, Frost FJ, Petersen HV, Picchi MA, Coultas DB. Health care utilization in chronic obstructive pulmonary disease. A casecontrol study in a health maintenance organization. Arch Intern Med. 2000;160(17):2653-2658.

21. Darkow T, Chastek BJ, Shah H, Phillips AL. Health care costs among individuals with chronic obstructive pulmonary disease within several large, multi-state employers. J Occup Environ Med. 2008;50(10): $1130-1138$.

22. Miller JD, Foster T, Boulanger L, et al. Direct costs of COPD in the U.S.: an analysis of Medical Expenditure Panel Survey (MEPS) data. COPD. 2005;2(3):311-318.

23. Menzin J, Boulanger L, Marton J, et al. The economic burden of chronic obstructive pulmonary disease (COPD) in a U.S. Medicare population. Respir Med. 2008;102(9):1248-1256.

24. Jensen MB, Fenger-Gron M, Fonager K, Omland O, Vinding AL, Hansen JG. Chronic obstructive pulmonary disease involves substantial health-care service and social benefit costs. Dan Med J. 2013; 60(1):A4557.

25. Nair K, Ghushchyan V, Van Den Bos J, et al. Burden of illness for an employed population with chronic obstructive pulmonary disease. Popul Health Manag. 2012;15(5):267-275.

26. Sharafkhaneh A, Petersen NJ, Yu HJ, Dalal AA, Johnson ML, Hanania NA. Burden of COPD in a government health care system: a retrospective observational study using data from the US Veterans Affairs population. Int JChron Obstruct Pulmon Dis. 2010;5:125-132.

27. Lin PJ, Shaya FT, Scharf SM. Economic implications of comorbid conditions among Medicaid beneficiaries with COPD. Respir Med. 2010; 104(5):697-704.

28. Halpern MT, Stanford RH, Borker R. The burden of COPD in the U.S.A.: results from the Confronting COPD Survey. Respir Med. 2003; 97(Suppl C):S81-S89.

29. Bilde L, Rud Svenning A, Dollerup J, Baekke Borgeskov H, Lange P. The cost of treating patients with COPD in Denmark - a population study of COPD patients compared with non-COPD controls. Respir Med. 2007;101(3):539-546.

30. Huber MB, Wacker ME, Vogelmeier CF, Leidl R. Excess costs of comorbidities in chronic obstructive pulmonary disease: a systematic review. PLoS One. 2015;10(4):e0123292.

31. Jansson SA, Backman H, Ronmark E, Lundback B, Lindberg A. Hospitalization due to co-morbid conditions is the main cost driver among subjects with COPD - a report from the population-based OLIN COPD study. COPD. 2015;12(4):381-389. 
32. Schwab P, Dhamane AD, Hopson SD, et al. Impact of comorbid conditions in COPD patients on health care resource utilization and costs in a predominantly Medicare population. Int JChron Obstruct Pulmon Dis. 2017;12:735-744.

33. Menn P, Heinrich J, Huber RM, et al. Direct medical costs of COPD an excess cost approach based on two population-based studies. Respir Med. 2012;106(4):540-548.

34. Global Initiative for Chronic Obstructive Lung Disease (GOLD) [webpage on the Internet]. Global Strategy for the Diagnosis, Management, and Prevention of Chronic Obstructive Pulmonary Disease [Updated 2016]. Available from: http://goldcopd.org/global-strategy-diagnosismanagement-prevention-copd-2016/. Accessed February 5, 2016.

35. Andersson F, Borg S, Jansson SA, et al. The costs of exacerbations in chronic obstructive pulmonary disease (COPD). Respir Med. 2002; 96(9):700-708.
36. Dhamane AD, Moretz C, Zhou Y, et al. COPD exacerbation frequency and its association with health care resource utilization and costs. Int $J$ Chron Obstruct Pulmon Dis. 2015;10(1):2609-2618.

37. Lisspers $\mathrm{K}$, Johansson G, Jansson C, et al. Improvement in COPD management by access to asthma/COPD clinics in primary care: data from the observational PATHOS study. Respir Med. 2014;108(9): $1345-1354$.

38. Holgate S, Bisgaard H, Bjermer L, et al. The Brussels Declaration: the need for change in asthma management. Eur Respir J. 2008;32(6): 1433-1442.

39. Pinnock H, Thomas M, Tsiligianni I, et al. The International Primary Care Respiratory Group (IPCRG) research needs statement 2010. Prim Care Respir J. 2010;19(Suppl 1):S1-S20.

\section{Publish your work in this journal}

The International Journal of COPD is an international, peer-reviewed journal of therapeutics and pharmacology focusing on concise rapid reporting of clinical studies and reviews in COPD. Special focus is given to the pathophysiological processes underlying the disease, intervention programs, patient focused education, and self management protocols.

\section{Dovepress}

This journal is indexed on PubMed Central, MedLine and CAS. The manuscript management system is completely online and includes a very quick and fair peer-review system, which is all easy to use. Visit http://www.dovepress.com/testimonials.php to read real quotes from published authors.

Submit your manuscript here: http://www.dovepress.com/international-journal-of-chronic-obstructive-pulmonary-disease-journal 